\title{
HOW TO APPLY THE ETHICAL REGULATOR THEOREM TO CRISES
}

\author{
Author / Auteur : \\ Mick ASHBY \\ ethics@ashby.de
}

\begin{abstract}
Résumé :
The Ethical Regulator Theorem defines nine requisites that are necessary and sufficient for a cybernetic regulator to be effective and ethical; regardless of whether the regulating agents are humans, machines, cyberanthropic hybrids, organizations, corporations, or government institutions. It provides a basis for systematically evaluating the adequacy of existing or proposed designs for systems that make decisions that can have ethical consequences. Because of this, the nine requisite dimensions can be used to conduct systematic root cause analysis of crises and to evaluate the adequacy of proposed interventions. Three of the theorem's requisites explicitly address ethics, integrity, and transparency, which are often overlooked in crisis situations.
\end{abstract}

Keywords / Mots-clés :

ethical regulator theorem, root cause analysis, ethical interventions, crises

\section{INTRODUCTION}

Cybernetics and systems theory has relied heavily on Ashby's Law of Requisite Variety, which has led practitioners to attempt to understand system inadequacies through the lens of variety, which has resulted in a tendency to overdiagnose problems in a regulator's effectiveness as being a "lack of variety". The overemphasis that has been put on variety has also resulted in force-multipliers (such as the use of money, mass media, and weapons) being classified as amplifiers of variety. The Ethical Regulator Theorem (ERT) shows that this explanation is incomplete, and provides a more powerful explanation.

The Good Regulator Theorem (Conant, 1970) is ambiguous because a regulator that is good at regulating is not necessarily good in an ethical sense. To avoid this ambiguity, this paper uses the term "effective" for the first meaning and "ethical" for the second.

The Good Regulator Theorem proved that every effective regulator of a system must be a model of that system, and the Law of Requisite Variety (Ashby, 1956) dictates the range of responses that an effective regulator must be capable of. However, having an internal model and a sufficient range of responses is insufficient to ensure effective regulation, let alone ethical regulation. And whereas being effective does not require being optimal, being ethical is absolute with respect to a particular ethical schema.

\section{THE ETHICAL REGULATOR THEOREM}

The Ethical Regulator Theorem identifies nine requisites that are necessary and sufficient for a cybernetic regulator to be effective and ethical (Ashby, 2018). Figure 1 illustrates how the nine requisite dimensions relate to each other to enable a cybernetic regulator to regulate a system ethically. 


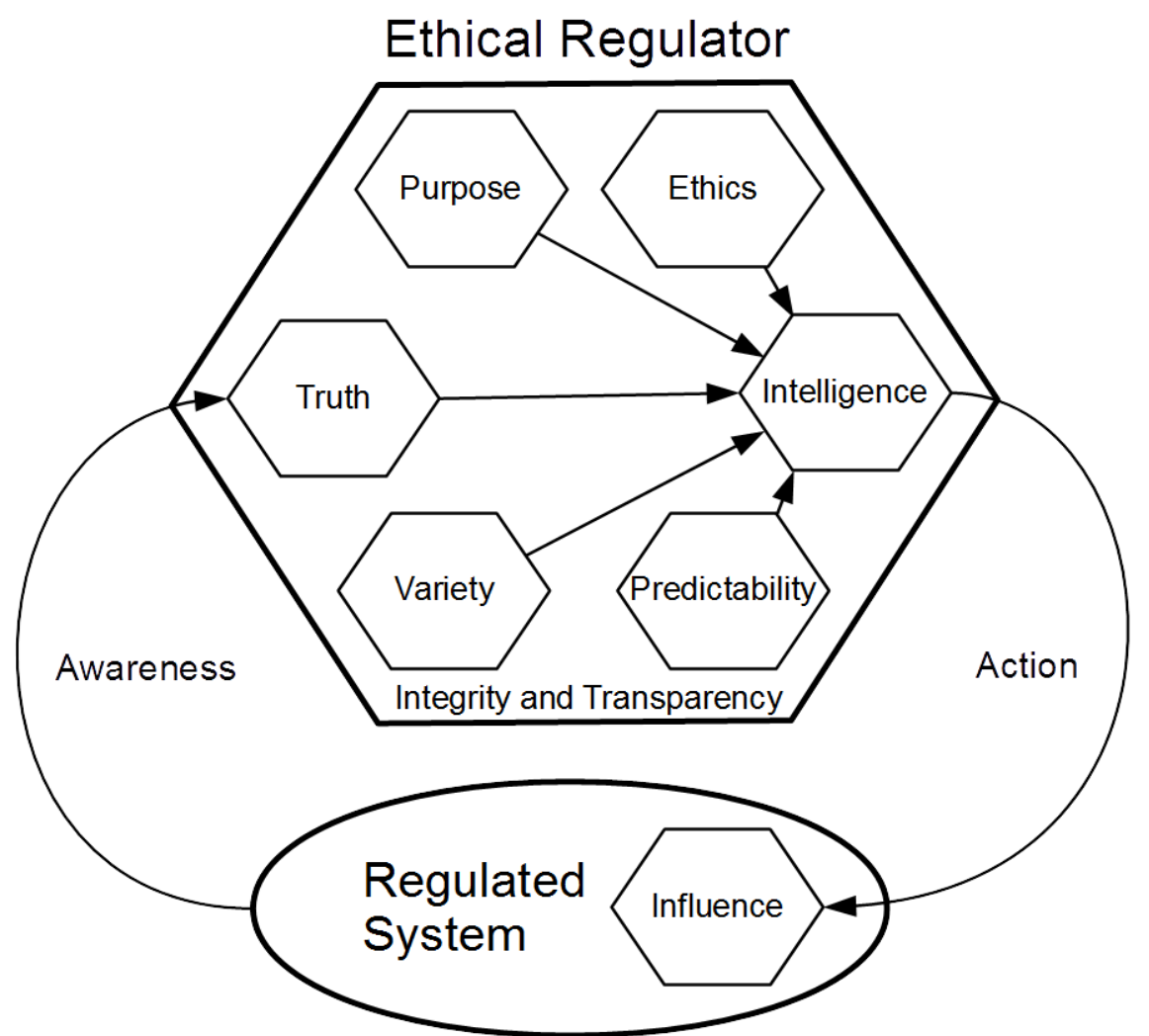

Figure 1. The Ethical Regulator System.

The nine requisites fall into three categories: Internal requisites, external requisites, and security requisites. Table 1 provides a summary of the nine requisite dimensions.

Table 1. Summary of Ethical Requisites.

\begin{tabular}{|l|l|l|l|}
\hline Category & $\begin{array}{l}\text { Requisite } \\
\text { Dimension }\end{array}$ & Summary & Example sub-categories \\
\hline Internal & Purpose & Prioritized goals. & $\begin{array}{l}\text { Primary goals, essential variable target } \\
\text { ranges, requirements to avoid specific } \\
\text { unintended consequences. }\end{array}$ \\
\cline { 2 - 4 } & Truth & $\begin{array}{l}\text { Truth about the past and } \\
\text { present. }\end{array}$ & $\begin{array}{l}\text { Information inputs, accuracy and timeliness, } \\
\text { knowledge, interpretations of information. }\end{array}$ \\
\cline { 2 - 4 } & Variety & Choice of possible actions. & $\begin{array}{l}\text { Abilities, possible actions, communications, } \\
\text { inaction, the timing of actions, preparations, } \\
\text { deciding to increase variety. }\end{array}$ \\
\cline { 2 - 4 } & Predictability & $\begin{array}{l}\text { Predictability of the future } \\
\text { effects of actions. }\end{array}$ & $\begin{array}{l}\text { Models, simulations, heuristics, experience, } \\
\text { model improvements, anticipation, instinct. }\end{array}$ \\
\cline { 2 - 4 } & Ethics & Prioritized rules. & $\begin{array}{l}\text { Laws, regulations, rules, strong cultural } \\
\text { conventions, stated public values, processes. }\end{array}$ \\
\cline { 2 - 4 } & Intelligence & $\begin{array}{l}\text { Ability to plan and choose } \\
\text { the best actions. }\end{array}$ & $\begin{array}{l}\text { Strategy, planning, decision-making, risk } \\
\text { analysis. }\end{array}$ \\
\hline
\end{tabular}




\begin{tabular}{|l|l|l|l|}
\hline Category & $\begin{array}{l}\text { Requisite } \\
\text { Dimension }\end{array}$ & Summary & Example sub-categories \\
\hline External & Influence & Ability to affect the system. & $\begin{array}{l}\text { Communication and control channels, mass } \\
\text { media, physical actions, use of machinery, } \\
\text { weapons, money, people, resources. }\end{array}$ \\
\hline Security & Integrity & $\begin{array}{l}\text { Real-time mechanisms to } \\
\text { detect ethical violations, } \\
\text { including attempts to } \\
\text { subvert any subsystems. }\end{array}$ & $\begin{array}{l}\text { Actually following the ethical rules without } \\
\text { exceptions. Defending all subsystems } \\
\text { against being compromised. }\end{array}$ \\
\cline { 2 - 5 } & Transparency & $\begin{array}{l}\text { Maintaining a secure audit } \\
\text { trail that can be analysed to } \\
\text { prove the ethical correctness } \\
\text { of every decision, contract, } \\
\text { resource usage, financial } \\
\text { transaction, and action } \\
\text { performed by the regulator } \\
\text { and its subsystems, } \\
\text { employees, and } \\
\text { subcontractors. }\end{array}$ & $\begin{array}{l}\text { System of record. } \\
\text { Provable that what it does is what it says it } \\
\text { foes (WIDIWISID). } \\
\text { For example, many people and organizations } \\
\text { actually violate the ethical schema that they } \\
\text { publicly claim to believe in. Such behaviour } \\
\text { is unethical. }\end{array}$ \\
\hline
\end{tabular}

\section{APPLICATION TO CRISIS ROOT CAUSE ANALYSIS}

If the nine requisite dimensions of the Ethical Regulator Theorem (ERT) are indeed necessary and sufficient for a regulating agent to be both effective and ethical at controlling a system, then when something is defined as being a crisis, the cause of the failure of any regulating agents to prevent or prepare for the crisis must fall into the same nine dimensions. Which implies that the root cause of failing to avert the crisis cannot lie outside the ERT's nine requisite dimensions.

When the system or problem space is systematically divided into the nine ERT dimensions, the resulting views of the problem space allow a better and balanced understanding of the problem space and a more complete coverage of the main root cause categories is ensured.

\section{Reduces cognitive complexity}

The complexity of real-world systems and problems often exceeds the ability of the human mind to consider all aspects. This cognitive overload can lead to some aspects getting disproportionately more attention and other aspects being completely overlooked.

By systematically considering a crisis or the failure to avert the crisis in the light of each of the nine ERT dimensions, one-at-a-time, the cognitive complexity is reduced by a factor of nine, which can make an otherwise cognitively intractable system or problem become significantly more manageable and makes it less likely that important aspects are overlooked.

\section{Evaluating ethical adequacy}

To be ethically adequate, a system or intervention must satisfy all nine requisite dimensions, including thorough consideration of ways to prevent bad actors from subverting each dimension. The following sections describe each dimension and provide example questions to illustrate the way that the nine dimensions can be utilized to investigate a system, a crisis, or a proposed intervention: 


\section{The Purpose dimension}

Purpose must be expressed as unambiguously prioritized goals. Without well-defined goals, the system cannot be effective and might randomly adopt or default to a goal that is unethical or only addresses part of the whole problem.

- Are the goals unambiguous?

- Are the goals prioritized?

- Do any goals conflict with each other?

- Are the goals ethical?

- Are the system's essential variables identified and their acceptable ranges defined?

- Do the goals explicitly address the need to avoid causing other predictable problems or unintended consequences?

- Is it clear who is responsible for achieving each goal?

- Did the response to a previous crisis suffer because the goals were inadequately defined or misunderstood?

- If so, have the goals been clarified?

\section{The Truth dimension}

Truth about the past and present is not just about information that is treated as facts or received as inputs, but also the reliability of any interpretations of such information. This is the regulator's awareness of the current situation, knowledge, and beliefs. If the information sources or interpretations are unreliable, and cannot be corrected, then the integrity of the system is in danger. An ethical regulator must be able to cope ethically with uncertainties and minimize the impact of unreliable information, misinterpretations, and deliberate misinformation as best as it can.

- How can the quality of the information inputs be improved?

- Can more information be obtained in real-time?

- What assumptions are not explicitly stated?

- Can we assume that those assumptions will always be true?

- Can alternative information sources be used to increase the reliability of information used?

- What might be the impact of acting based on unreliable information?

- Who might have an incentive to be dishonest?

- What prevents a bad actor from feeding distorted information into the system?

- Did the response to a previous crisis suffer because of a lack of accurate or timely information?

- If so, have the information deficits been improved?

\section{The Variety dimension}

Variety in the range of possible actions must be as rich as the range of potential disturbances or situations. This is known as the Law of Requisite Variety (Ashby, 1956).

- Are the choice of possible actions sufficient to achieve the goals?

- Can more possible actions, responses, and strategies be generated to enable a better response to situations?

- Did the response to a previous crisis suffer because of a lack of choices of possible actions or strategies?

- If so, have the range of choices and strategies been expanded? 


\section{The Predictability dimension}

Predictability requires a sufficiently accurate model and understanding of the system being regulated, including the regulating agents, that can be used to rank the actions and strategies that will give the best outcome. The need for a regulator to have an internal model is known as the Good Regulator Theorem (Conant and Ashby, 1970).

- Is the model of the system well understood?

- Can the model of the system be improved?

- Can more experience and heuristic knowledge be captured explicitly in the model?

- Did the response to a previous crisis suffer because the effects or side-effects of actions were not fully understood?

- If so, has the model of the system and the decision makers' and action takers' understanding of the system been improved?

\section{The Ethics dimension}

Ethical constraints are defined by the laws, regulations, rules, strong cultural conventions, stated public values, and processes that must be obeyed. These must include basic ethics such as honesty, respecting human rights, and not causing humans beings harm through action or through inaction.

- Are the ethical constraints that apply clear and understood by those making decisions and taking actions?

- Are there any ambiguities?

- Are any of the purpose goals or variety of actions at conflict with the ethical constraints?

- Did the response to a previous crisis suffer because ethical constraints were inadequate, misunderstood, or violated?

- If so, have these aspects been improved?

\section{The Intelligence dimension}

Intelligence must be applied to the previous five types of information to select the most rational and effective/ethical action from the set of possible actions and strategies that achieve the purpose as effectively as possible without violating any ethical constraints, or through inaction, allowing any ethical constraints to be violated.

- Do the decision-making people have the necessary training and experience?

- Can existing strategy and planning be improved?

- Are the data analysis processes adequate?

- Did the response to a previous crisis suffer because of an inability to process or assimilate information?

\section{The Influence dimension}

Influence is the existence of pathways to transmit the effects of the selected actions to the regulated system. Influence can be communication channels, which can be amplified by using mass media such as as radio, internet, and television. In some instances influence requires the availability of resources to make the selected actions and strategies effective.

- Do adequate channels exist to transmit the effects of selected actions to the system being regulated?

- Are the communication channels sufficient?

- Are appropriate resources, such as machinery, food, water, money, and people available?

- Did the response to a previous crisis suffer because of insufficient influence or resources to make the selected actions and strategies effective? 


\section{The Integrity dimension}

Integrity of the systems and subsystems must be assured through features such as resistance to tampering, intrusion detection, and theft detection. Adequate monitoring mechanisms must detect if any ethical constraint is violated, and if necessary, preserve evidence and immediately notify appropriate authorities.

- Are resources appropriately (physically or digitally) protected?

- Have all actors sworn an oath to uphold the laws, human rights, and ethical principles?

- Are real-time monitoring processes and mechanisms in place to detect violations of ethics?

- Is there a subsystem responsible for receiving reports of ethical violations and acting on them swiftly?

- Did the response to a previous crisis suffer because of theft, corruption, or a lack of monitoring of ethical compliance?

- If so, have appropriate improvements been implemented?

\section{The Transparency dimension}

For a system to be truly ethical, it must be possible to prove retrospectively that it acted ethically with respect to the appropriate ethics. This requires a sufficient audit trail of decisions, actions, and the movement of valuable resources and money to detect problems in real-time, deter theft and corruption, and allow detailed retrospective analysis of decisions, effectiveness, and resource allocation.

- Is the audit trail adequate?

- How can the system ensure that theft and corruption can be detected and proved?

- Did the post-mortem analysis of a previous crisis suffer because of a lack of information?

- If so, is the missing information now systematically collected and recorded?

\section{Systematic evaluation of proposed interventions}

Systematically evaluating any proposed solutions in each of the nine ERT dimensions can help to ensure the effectiveness and ethical adequacy of any interventions. This approach ensures that proposed solutions are holistic and reduces the risk that aspects of an intervention might be overlooked and cause unintended consequences.

For example, in the urgent rush to deal with a crisis, interventions are often less effective than they could have been because the dangers of unintended consequences such as theft and corruption are not considered and prevented. As a result of neglecting to consider all dimensions of the problem, money is stolen, food and medicines end up on the black market, or U.N. peacekeepers spread diseases to the communities that they are sent to help.

\section{RÉFÉRENCES}

Ashby, Mick (2018). Cybernetics 3.0: Ethical Systems, http://ashby.de/Ethical Regulators.pdf Ashby, W. Ross (1956). An Introduction to Cybernetics, Chapman and Hall, London.

Conant, Roger C., and Ashby, W. Ross (1970). Every good regulator of a system must be a model of that system, Int. J. Systems Sci. 1(2):89-97. 